\title{
RÉGIMEN DE ALEGACIÓN Y PRUEBA DEL DERECHO EXTRANJERO Y LEX LOCI DELICTI COMMISSI. COMENTARIO A LA SENTENCIA DE LA AUDIENCIA PROVINCIAL DE LAS ISLAS BALEARES DE 13 DE DICIEMBRE DE 2018
}

\author{
SCHEME OF ALLEGATION AND PROOF OF FOREIGN LAW \\ AND LEX LOCI DELICTI COMMISSI. COMMENT ON \\ THE JUDGMENT OF THE SPANISH COURT OF APPEAL \\ OF THE BALEARIC ISLANDS OF 13 DECEMBER 2018
}

\author{
Alfonso Ortega GimÉneZ* \\ Profesor Contratado Doctor de Derecho internacional privado \\ Universidad Miguel Hernández de Elche (acreditado a profesor titular de Universidad) \\ ORCID ID: 0000-0002-8313-2070
}

Recibido: 23.05.2019 / Aceptado: 11.06.2019

DOI: https://doi.org/10.20318/cdt.2019.5014

\begin{abstract}
Resumen: El Derecho extranjero debe alegarse y probarse en lo que a su existencia, vigencia y contenido se refiere, permitiendo al Tribunal valerse de los medios de averiguación que estime necesarios para su aplicación. Es a la parte que lo invoque a quien corresponde demostrar el contenido y su vigencia. Así se aprecia en la Sentencia de la Audiencia Provincial de las Islas Baleares de 13 de diciembre, de 2018, donde la parte demandada presenta dos informes sobre el Derecho extranjero; el Tribunal rechaza ambos informes señalando que en ellos no se aprecia ninguna especialidad del derecho extranjero sobre la titularidad del bien; respecto al informe sobre la legitimación pasiva conforme al derecho de Curazao y Holanda resultaba innecesario tratándose de una obligación no contractual, por lo que en virtud de la Lex Loci Delicti Commissi será de aplicación la Ley española, al haberse producido el daño en territorio nacional.

Palabras clave: Derecho extranjero, Lex Loci Delicti Commissi, obligaciones extracontractuales.
\end{abstract}

Abstract: The foreign Law must be alleged and proven as to its existence, validity and content, allowing the Court to use the means of inquiry it deems necessary for its application. It is the party that invokes it to whom it corresponds to demonstrate the content and its validity. This is seen in the Judgment of the Spanish Court of Appeal of the Balearic Islands of 13 December 2018, where the presents two reports on foreign law; the Court rejects both reports noting that they do not see any specialty of foreign law on the ownership of the property; Regarding the report on passive legitimation under the law of Curaçao and the Netherlands, it was unnecessary in the case of a non-contractual obligation, so under the Lex Loci Delicti Commissi the Spanish Law will apply, since the damage occurred in the national territory.

Keywords: Foreign law, Lex Loci Delicti Commissi, non-contractual obligations.

*alfonso.ortega@umh.es 
Sumario: Planteamiento. II. Hechos, alegaciones de las partes y cuestiones controvertidas. III. Alegación y prueba del derecho extranjero. 1. La necesidad de prueba del Derecho extranjero. 2. Forma de probar el Derecho extranjero. 3.Objeto de la prueba del Derecho extranjero. 4. Medios de prueba del Derecho extranjero. 5. Consecuencias de la no alegación o prueba del Derecho extranjero. IV. Aplicación de la Lex Loci Delicti Commissi. V. Consideraciones finales.

\section{Planteamiento}

1. Determinar cuándo, por qué y cómo deben aplicarse las leyes extranjeras ha sido, es y será un tema de notable interés para el Derecho internacional privado. El Derecho extranjero tiene que ser introducido a través de los mecanismos previstos para la prueba dentro del proceso. La cuestión de la aplicación del Derecho extranjero ha entrado en una nueva dimensión con ocasión de la regulación ofrecida sobre el tema, en su día, por la Ley 1/2000, de 7 de enero, de Enjuiciamiento Civil (LEC) ${ }^{1}$ : los artículos 281.2 y 282 dan cuerpo a un sistema de prueba del Derecho extranjero de textura abierta. El artículo 281.2 obliga a alegar y probar el Derecho extranjero en su contenido y vigencia, permitiendo al tribunal valerse de los medios de averiguación que estime necesarios para su aplicación; y, hoy, con los artículos 33 y 34 de la Ley 29/2015 de Cooperación Jurídica Internacional (en adelante LCJI) ${ }^{2}$.

2. En los casos en los que se aplica Derecho extranjero, la parte interesada en su aplicación deberá: primero, fundamentar su demanda en el Derecho extranjero y, segundo, probar el Derecho extranjero, una vez justificados esos dos extremos, dependerá del Juez la aplicación, a cuyo fin podrá desplegar la actividad que estime necesaria. El contenido no puede limitarse a presentar un Código normativo, sino toda la legislación aplicable al caso, la general y especial, de acuerdo con los mecanismos de interpretación propios de la Legislación en la que estén integradas las normas cuya aplicación se pretenda.

En el caso en el que las partes argumenten en base al Derecho extranjero, pero no lo prueban: el tribunal deberá realizar dos operaciones: a) En la audiencia previa al juicio, advertirá a las partes en este sentido: éstas deben proponer la práctica de la prueba del Derecho extranjero. El tribunal advertirá a las partes de las consecuencias que tendrá el no hacerlo (= artículo 429.1.II de la LEC); y b) Si pese a ello, las partes no prueban el Derecho extranjero, éste no podrá aplicarse y el tribunal tampoco deberá probarlo. Dictará sentencia y desestimará las pretensiones de las partes.

\section{Hechos, alegaciones de las partes y cuestiones controvertidas.}

3. La Audiencia Provincial de Baleares en el caso que nos ocupa es un vademécum de criterios iusinternacionalprivatistas: determinación de la competencia judicial internacional para conocer de una reclamación de responsabilidad civil extracontractual (= forum damni), recurriendo a la lex fori regit processum para determinar la ley procesal aplicable al supuesto; aplicación del régimen de alegación y prueba del Derecho extranjero; y, determinación de la ley aplicable al supuesto concreto (= lex loci delicti commissi).

4. La parte actora (TELEFÓNICA DE ESPAÑA S.A.U.) se alza contra la resolución de instancia que desestima su pretensión de condena a las demandadas (VICTORIUS SHIPPING COMPANY N.V. y asegurado en KUIPER VERZEKERINGEN B.V.) al abono de 376.367,86 euros. La pretensión se fundamenta en que en fecha de 16 de junio de 2013 el buque "Dwinger", propiedad de VICTORIUS SHIPPING COMPANY N.V. y asegurado en KUIPER VERZEKERINGEN B.V, hallándose fondeado en Cala Jondal, enganchó un cable submarino de fibra óptica propiedad de la actora que enlazaba las islas de Ibiza y Formentera, privando a éstas del servicio de datos (ADSL y $3 \mathrm{G}$ ) prestado por la actora. El coste de la reparación de los daños y el lucro cesante derivado del siniestro asciende a la cantidad que reclama.

\footnotetext{
${ }^{1}$ BOE núm. 7, de 8 de enero de 2000.

${ }^{2}$ BOE núm. 182, de 31 de julio de 2015.
} 
La resolución de instancia desestima la demanda por no estimar acreditado que los daños en el cable submarino fueran causados por el buque "Dwinger", que éste fuera propiedad de la codemandada VICTORIUS SHIPPING COMPANY N.V, ni que el daño fuera imputable a la entidad demandada. Partiendo de que no es controvertido que el cable submarino que identifica la actora sufriera daño, la primera cuestión que se impone abordar es la relativa a si es imputable al buque "Dwinger" en la medida en que la demanda se desestima por no considerar acreditado que así fuera. Para ello, y dado que en el procedimiento concurre elemento extranjero atendido el pabellón del "Dwinger" y la nacionalidad holandesa de las entidades codemandadas, debe precisarse la normativa aplicable. La legislación procesal española es la aplicable al procedimiento en curso conforme al artículo 3 de la Ley de Enjuiciamiento Civil.

5. La naturaleza extracontractual de la responsabilidad que se pretende hace aplicable el Reglamento (CE) No 864/2007 del Parlamento Europeo y del Consejo, de 11 de julio de 2007, relativo a la Ley aplicable a las obligaciones extracontractuales (= Reglamento "Roma II") ${ }^{3}$, conforme a sus artículos 1 a 3; lo que, a su vez, determina de acuerdo con su artículo 4, la aplicación de la Ley española al haberse producido el daño en territorio nacional.

Partiendo de la normativa aplicable y del nuevo examen de la prueba practicada, debe considerarse que fue el buque "Dwinger" el que dañó el cable submarino. Así se recoge en las pruebas realizadas como que la nave se hallara localizada y fondeada en el lugar que coincide con la localización del cable submarino y que coincide con en el diario de navegación del buque incorporado a las actuaciones $\left(38^{\circ}, 51,733 \mathrm{~N}\right)$, por los informes de los peritos se descarta de que el daño fuese producido por otras embarcaciones debido a sus características. El propio Capitán de la nave, reconoció ante Capitanía Marítima que hallándose fondeada, no pudo abandonar el lugar por no poder subir el ancla al haberse enganchado, viéndose obligado a pernoctar para el día siguiente recabar la ayuda de un buzo quien señalo que el ancla se hallaba enganchada a un cable submarino, lo que se aprecia en las fotografías que tomó.

Confirmado que el daño fue causado por el buque se analiza el motivo de oposición de la codemandada VICTORI US SHIPPING COMPANY N.V. quien señala no ser su titular al tiempo de ocurrir los hechos, comprobado el certificado de registro, figura como titular del buque VICTORIUS SSHIPPING COMPANY N.V. Pese a esta prueba en su escrito de contestación a la demanda niega ser la titular, sin identificar a quien pudiera serlo, no acompañando documentación alguna y anunciando la incorporación de dos dictámenes de expertos en Derecho neerlandés sobre la titularidad del bien y la identidad de las personas jurídicas. Se incorporaron los informes con anterioridad a la celebración de la audiencia previa conforme al artículo 337.2 de la LEC. El informe que se incorpora se fundamenta en los asientos registrales que se acompañan, sin añadir ninguna especialidad del Derecho extranjero sobre la titularidad del bien en los términos de los artículos 33 y 34 de la LCJI, limitándose a señalar que la información que ofrece el registro es de acceso público. En cuanto al segundo de los informes relativo a la legitimación de la demandada, como se expuso anteriormente, conforme los artículos 4 y 15 Reglamento "Roma II", tratándose de obligación no contractual, la determinación de las personas que puedan considerarse responsables por sus propios actos se rige por la ley del lugar en que se produjo el daño, por lo que un informe sobre la legitimación pasiva conforme al derecho de Curazao y Holanda resulta impertinente conforme a los artículos 281 y 282 de la LEC. Partiendo de las anteriores consideraciones, debe apreciarse la legitimación pasiva de la entidad demandada ya que la parte demandada contesta a la demanda sin especificar la causa por la que dejó de ser titular del buque, sin identificar a quien pudiera serlo y sin acompañar documentación alguna al respecto.

6. Por otro lado, la codemandada KUIPER VERZEKERINGEN B.V. niega su legitimación pasiva, sosteniendo que es mero intermediario, no entidad aseguradora, presentando dos informes de expertos: uno, sobre las actividades a que se dedica la demandada; y, otro, sobre si debe responder del siniestro. Al escrito de contestación a la demandada no se incorporó documentación alguna y, ni siquiera, se identificó qué entidad pudiera ser la aseguradora pese a sostener la codemandada que es una mera intermediaria. Por lo que se considera la legitimación pasiva por la actividad que señala en su página

${ }^{3}$ DOUE núm. 199, de 31 de julio de 2007. 
en la que figura bajo su denominación social "seguros de yates". También resulta de los correos que remitió una vez tuvo conocimiento del siniestro y en los que se identifica como aseguradora del velero, ofreciendo información sobre la responsabilidad contratada y solicitándola sobre los daños que pudiera haber causado el buque.

La resolución de instancia niega la responsabilidad que se reclama en la demanda, considerando que la actora, como propietaria del cable, asumió el riesgo de que éste resultara dañado al no limitar la zona de fondeo, hasta después de ocurrido el siniestro, apoyándose en diversas sentencias como la de 13 julio de 2017 (objetivación de la culpa en el ámbito de la responsabilidad extracontractual) en el mismo sentido se pronuncian las sentencias del Tribunal Supremo de 15 de junio de 2001 y de 24 de julio del mismo año, entre otras muchas. Sobre la diligencia que exija la naturaleza de la obligación y corresponda a las circunstancias del tiempo y del lugar se mencionan las sentencias del Tribunal Supremo de 6 de febrero y 25 de mayo de 2001. Sobre la teoría del riesgo las sentencias del Tribunal Supremo de 19 de junio de 2000 y 17 de octubre de 2001, entre otras muchas. Toda esta evolución jurisprudencial hace referencia al elemento subjetivo o culpa correspondiendo al perjudicado y a la plena acreditación tanto del daño -elemento objetivo- como del nexo de causalidad -elemento causal-, pues no hay responsabilidad si no se acredita directa o indirectamente cual fuera el acto inicial desencadenante del evento lesivo STS de 18 de diciembre de 1989, sentencias del Tribunal Supremo de 10 de marzo de 1987 y 2 de septiembre de 1997. En igual sentido señala la sentencia del Alto Tribunal de 30 de noviembre de 2001, que "la determinación del nexo causal no puede fundarse en conjeturas o posibilidades, y aunque no siempre se requiere la absoluta certeza, por ser suficiente (en casos singulares) un juicio de probabilidad cualificada".

7. Considerando los elementos expuestos, no se comparte la apreciación del Magistrado de instancia. Con independencia de que en la Cala de autos no estuviera prohibido fondear en el momento en que ocurre el siniestro, lo que no depende de la parte actora sino de la Autoridad marítima correspondiente, no es controvertido que la existencia y localización del cable submarino se hallaban indicadas en todas las cartas náuticas, sirviendo de advertencia a las embarcaciones que navegaban por la zona. Ello obligaba a quienes navegaban por la Cala a adoptar las oportunas precauciones para evitar no solo el daño al cableado, sino, incluso, a la propia embarcación. No consta que se adoptara precaución alguna en el supuesto de autos, reconociendo incluso el Capitán que intentó subir el ancla enganchada al fondo, viéndose obligado a abandonar la maniobra ante la imposibilidad de izarla. Ello evidencia que el responsable del buque no tomó conciencia en ningún momento de la causa que le impedía abandonar el lugar, pese a que la existencia del cable se hallaba debidamente reflejada en la documentación náutica.

Esa falta de previsión y cautela pese a la advertencia contenida en documentación de obligado conocimiento para la tripulación de una nave, hacen responsable del daño a la propietaria del buque y a su entidad aseguradora.

8. En suma, la Sala estima el recurso de apelación interpuesto por TELEFÓNICA DE ESPAÑA S.A.U. contra la Sentencia dictada en fecha en fecha de 12 de junio de 2018 por el Juzgado de Primera Instancia $\mathrm{N}^{\circ} 1$ de Ibiza. En consecuencia, se revoca la expresa resolución dejándola sin efecto, y en su lugar, se estima la demanda interpuesta por TELEFÓNICA DE ESPAÑA S.A.U. contra VICTORIUS SHIPPING COMPANY N.V. y KUIPER VERZEKERINGEN B.V, condenando a éstas a abonar a la parte actora la cantidad de 375.262,86 euros. Se impone a la parte demandada el pago de las costas procesales causadas en la instancia, sin hacer expresa declaración respecto a las causadas en esta alzada. Se acuerda la devolución del depósito constituido para la interposición del recurso.

\section{Alegación y prueba del Derecho extranjero.}

\section{La necesidad de prueba del Derecho extranjero}

9. El artículo 281 de la LEC exige la prueba del Derecho extranjero porque el tribunal no tiene la obligación de conocer la Ley extranjera, sólo está obligado a conocer las normas jurídicas españolas 
escritas. Es por esta razón que cada vez que tenga que aplicarse un Derecho extranjero, éste deberá ser probado en el concreto proceso en que se invoque.

Para clarificar la situación actual sobre la prueba del Derecho extranjero en los tribunales españoles es necesario iniciar una lectura pormenorizada del artículo 281 LEC:

“1. La prueba tendrá como objeto los hechos que guarden relación con la tutela judicial que se pretenda obtener en el proceso.

2. También serán objeto de prueba la costumbre y el derecho extranjero. La prueba de la costumbre no será necesaria si las partes estuviesen conformes en su existencia y contenido y sus normas no afectasen al orden público. El derecho extranjero deberá ser probado en lo que respecta a su contenido y vigencia, pudiendo valerse el tribunal de cuantos medios de averiguación estime necesarios para su aplicación.

3. Están exentos de prueba los hechos sobre los que exista plena conformidad de las partes, salvo en los casos en que la materia objeto del proceso esté fuera del poder de disposición de los litigantes.

4. No será necesario probar los hechos que gocen de notoriedad absoluta y general."

Este artículo nos posiciona la prueba del Derecho extranjero fuera de los hechos procesales, y de donde se extrae que "el Derecho extranjero debe probarse en lo que respecta a su contenido y vigencia, pudiendo valerse el Tribunal de cuantos medios de averiguación estime necesarios para su aplicación". En este precepto se diferencia entre la "prueba del contenido y vigencia" del Derecho extranjero, cuya obligación recae sobre la parte que lo alega, y la "aplicación" del mismo, que corresponde al tribunal una vez que ya se ha realizado (o intentado) la prueba por las partes. ${ }^{4}$

Dado que debe alegar y probar el Derecho extranjero la parte que invoque su aplicación, resultará irrelevante si ésta ostenta la posición de demandante o de demandado. ${ }^{5}$

Así ocurre en esta Sentencia de la Audiencia Provincial de Baleares de 13 de diciembre de 2018, cuando la parte demandada acompañó dos informes en la contestación a la demanda. En el primero de ellos, VAN TRAA AADVOCATEN NV se pronuncia sobre la titularidad de la embarcación acompañando el certificado holandés de registro. En el segundo informe, los expertos se pronuncian sobre la legitimación pasiva de la demandada.

Con la LCJI se ha buscado incidir en uno de los aspectos más controvertidos del sistema español de alegación y prueba del Derecho extranjero. Nuestro sistema se caracteriza por ser un sistema mixto que combina el principio de alegación y prueba a instancia de parte con la posibilidad de que el tribunal complete dicha prueba, valiéndose de cuantos medios de averiguación estime necesarios. El artículo 33 de la LCJI señala expresamente lo siguiente:

“1. La prueba del contenido y vigencia del Derecho extranjero se someterá a las normas de la Ley de Enjuiciamiento Civil y demás disposiciones aplicables en la materia.

2. Los órganos jurisdiccionales españoles determinarán el valor probatorio de la prueba practicada para acreditar el contenido y vigencia del Derecho extranjero de acuerdo con las reglas de la sana crítica.

3. Con carácter excepcional, en aquellos supuestos en los que no haya podido acreditarse por las partes el contenido y vigencia del Derecho extranjero, podrá aplicarse el Derecho español.

4. Ningún informe o dictamen, nacional o internacional, sobre Derecho extranjero, tendrá carácter vinculante para los órganos jurisdiccionales españoles."

Decantándose por la aplicación de la lex fori, que es la tradicional en nuestro sistema y la mayoritaria en los sistemas de Derecho internacional privado de nuestro entorno. Es, asimismo, la solución

${ }^{4}$ Vid. SAP de Asturias de 10 febrero de 2012, que señala que: "lo cierto es que quien invoque el derecho extranjero debe probar su contenido y vigencia, conforme establece el artículo 281.2 de la Ley de Enjuiciamiento Civil, siendo así que en el presente caso la actora solo ha invocado en defensa de sus intereses el Derecho español, la aseguradora demandada sostuvo en su contestación que la legislación aplicable era la marroquí, pero lejos de invocar siquiera las concretas normas de la legislación marroquí que pudieran resultar aplicables (...) se limitaba a invocar el principio iura novit curia (...) el tribunal termina por aplicar la legislación española" (Id vLex: VLEX-362809702).

5 Vid. STS de 27 de diciembre de 2006, que señala que "existe una numerosa y consolidada jurisprudencia sobre la necesidad de probar, por quien se alega o invoca o postula la aplicación del Derecho extranjero, la existencia, el contenido y la vigencia de la norma cuya aplicación se pretende. Es lo que decía la Sentencia 31 de diciembre de 1994, con expresa referencia de que la prueba corresponde a quien invoca el Derecho extranjero" (Id vLex: VLEX-26673136). 
que más se adecua a la jurisprudencia constitucional de la que se deduce que la desestimación de la demanda conculcaría en determinados supuestos el derecho a la tutela judicial efectiva.

Debe entenderse que la falta de prueba del Derecho extranjero dentro de un proceso judicial es algo excepcional que solo sucederá cuando las partes no consigan probar el Derecho extranjero y sin olvidar la posibilidad de que el tribunal coopere en la acreditación de dicho contenido. Además, han de respetarse los sistemas específicos que en leyes especiales prevean otras soluciones iguales o diversas, por referencia, por ejemplo, a la normativa de protección de consumidores y usuarios, así como a la registral civil. Además, el artículo 33 de la LCJI clarifica la interpretación del valor probatorio de la prueba practicada con arreglo a los criterios de la sana crítica y determina el valor de los informes periciales sobre la materia. No será necesaria la prueba del Derecho extranjero por las partes cuando el tribunal, por alguna razón, tiene ya un exacto conocimiento de tal derecho, pues en ese supuesto deberá aplicarlo de oficio ${ }^{6}$. Por otro lado, no será necesario probar el Derecho extranjero cuando la parte lo invoca como mero apoyo de sus pretensiones y no para que sea aplicado por el tribunal español al fondo del asunto.

En la SAP de Baleares de 13 de diciembre de 2018, respecto a las pruebas de derecho extranjero aportadas por la parte demandada, señala que los informes sobre el Derecho extranjero resultaban innecesarios ya que el informe que sobre ello se incorpora se fundamenta en los asientos registrales que se acompañan, sin añadir ninguna especialidad del Derecho extranjero sobre la titularidad del bien en los términos de los artículos 33 y 34 de la LCJI, limitándose a señalar que la información que ofrece el registro es de acceso público. En cuanto al segundo de los informes relativo a la legitimación de la demandada, conforme los artículos 4 y 15 del Reglamento "Roma II", tratándose de obligación no contractual, la determinación de las personas que puedan considerarse responsables por sus propios actos se rige por la ley del lugar en que se produjo el daño, por lo que un informe sobre la legitimación pasiva conforme al derecho de Curazao y Holanda resultaba impertinente conforme a los artículos 281 y 282 de la LEC.

\section{Forma de probar el Derecho extranjero}

10. Debemos recordar que el Derecho extranjero es un "hecho procesal" con unas características especiales, pero que no deja de ser un hecho y, como tal, debe ser alegado y probado por las partes.

El artículo 33.1 de la LCJI determina que la prueba del contenido y vigencia del Derecho extranjero se someterá a las normas de la LEC y de otras disposiciones sobre la materia. En principio, en materia de aportación de pruebas, la LEC opta por el principio de aportación de parte, existen, a nuestro juicio, excepciones que pueden desembocar en la decisión de acordar de oficio la práctica de pruebas determinadas o la aportación documental cuando lo establezca la Ley. El propio artículo 281.2 de la LEC dice: "Sin embargo, el tribunal podrá acordar, de oficio, que se practiquen determinadas pruebas o que se aporten documentos, dictámenes u otros medios e instrumentos probatorios, cuando así lo establezca la ley". El artículo 281.2 LEC, constituye una norma meramente potestativa de modo que, si bien permite al juzgador a averiguar por todos los medios que estime necesarios el Derecho extranjero aplicable, no le obliga a ello. ${ }^{7}$

La regulación de la LEC en relación con la alegación y prueba del Derecho extranjero es una regulación "de líneas generales". Es decir, puede afirmarse que el artículo 281.2 de la LEC contiene un sistema de "textura abierta" en relación con la prueba del Derecho extranjero. Ello significa que el legislador español ha renunciado a elaborar en la LEC una regulación exhaustiva y minuciosa de la prueba del Derecho extranjero.

Existen distintos mecanismos previstos en convenios internacionales que permite al tribunal acreditar el Derecho extranjero, como ser la Convención Interamericana sobre Prueba e Información

\footnotetext{
${ }^{6}$ Vid. STS de 10 de junio de 2005, que señala expresamente que "en nuestro ordenamiento, el Tribunal está facultado para valerse de cuantos medios de averiguación estime necesarios para la aplicación del derecho extranjero (...) lo que significa tanto como que debe aplicarlo si es que lo conoce y, al final, que de hecho la aportación de parte sólo sea necesaria para suplir aquella información". (Id vLex: VLEX-18040586)

${ }^{7}$ Este artículo precisa que "el derecho extranjero deberá ser probado en lo que respecta a su contenido y vigencia, pudiendo valerse el tribunal de cuantos medios de averiguación estime necesarios para su aplicación”. Además, el artículo 282 LEC establece que "el tribunal podrá acordar, de oficio, que se practiquen determinadas pruebas o que se aporten documentos, dictámenes u otros medios e instrumentos probatorios, cuando así lo establezca la ley".
} 
acerca del Derecho extranjero, hecha en Montevideo el 8 mayo 1979. ${ }^{8}$ Instrumento de Adhesión de España del 10 de diciembre de $1987^{9}$, el Convenio europeo acerca de la Información sobre el Derecho extranjero de 7 de junio de $1968^{10}$. Instrumento de adhesión de 2 de octubre de 1973 de España ${ }^{11}$, Protocolo adicional al Convenio europeo acerca de la información sobre Derecho extranjero, hecho en Estrasburgo el 15 de marzo de $1978^{12}$, así como diferentes convenios bilaterales con distintos países como Méjico, Marruecos, Republica Checa, China, Bulgaria, Brasil, etc. ${ }^{13}$

\section{Objeto de la prueba del Derecho extranjero}

11. Otro aspecto a determinar es ¿qué elementos del Derecho extranjero en cuestión deben ser probados?, es decir, ¿cuál debe ser el alcance objetivo de la prueba? En este sentido debe probarse el contenido del Derecho extranjero y su vigencia en el momento de aplicarlo.

Dos tesis se han sostenido respecto al alcance de la prueba del Derecho extranjero. La primera de ellas, es la denominada "tesis de la prueba mínima", en función de la cual se debe entender literalmente el precepto, por lo que sólo debe probarse el contenido del Derecho extranjero y su vigencia en el momento de aplicarlo. En segundo lugar, encontramos la "tesis de la prueba exhaustiva", que ha sido mantenida mayoritariamente por la práctica jurisprudencial española, entendiendo que no sólo debe probarse el "contenido y vigencia" del Derecho extranjero, sino que estos conceptos deben interpretarse de una forma extensiva, debiendo probar la parte interesada otros extremos del mismo. ${ }^{14}$

Por lo que respecta a la doctrina, se sostiene que de los requerimientos jurisprudenciales en cuanto a esta materia se puede extraer que deben probarse los siguientes elementos: ${ }^{15}$

a) El contenido literal del Derecho material extranjero: se debe acreditar el contenido literal de las normas materiales de tal Derecho, no basta con una "mera cita aislada de disposiciones extranjeras" 16 ;

b) El contenido literal de las normas de conflicto extranjeras: se debe probar que las normas de conflicto del derecho invocado no provocan un "reenvío" en favor del derecho español, pues en caso contrario el juez español no estaría fallando de la misma forma que lo haría un tribunal del país en cuestión ${ }^{17}$. Cabe decir que la prueba de este extremo no ha sido requerida por muchos tribunales;

\footnotetext{
${ }^{8}$ BOE núm. 11, de 13 de enero de 1988.

${ }^{9}$ Es un texto internacional elaborado en el seno de la CIDIP que dispone un sistema de cooperación entre los Estados que son parte del mismo, para acreditar, mediante prueba documental, pericial e informes del Estado requerido, el texto, la vigencia y el alcance de su Derecho. Este mecanismo se puede llevar a cabo directamente entre las autoridades judiciales, o por medio de la autoridad central de los Estados.

${ }^{10}$ Más conocido como Convenio de Londres, establece un sistema de auxilio y colaboración judicial internacional en lo que respecta a la información del Derecho Extranjero.

${ }^{11}$ BOE núm. 240, de 7 de octubre de 1974.

12 BOE núm. 150, de 24 de junio de 1982.

${ }^{13}$ España ha suscrito un importante número de convenios bilaterales en los que se incluyen obligaciones recíprocas de información sobre el contenido de los respectivos ordenamientos jurídicos. México, 1984; República Checa, 1987; Uruguay, 1987; Rusia, 1990; China, 1992; Bulgaria, 1993; Marruecos, 1997; Tailandia, 1998; República Dominicana, 2003; y Argelia, 2005.

${ }^{14}$ Vid., A.L.Calvo Caravaca/J.Carrascosa González, Derecho internacional privado, Granada, Comares, $14^{\circ}$ ed., 2013, 2 vols. I, vol. I, pp. 443 y ss.

15 Vid. A.L.Calvo Caravaca/J.Carrascosa González, op. cit., pp. 465-466.

${ }^{16} \mathrm{Vid}$. SAP de Baleares de 27 de abril de 2006. En esta Sentencia una de las partes alega la aplicación del Derecho alemán. En primer lugar, la Audiencia Provincial dispone que tal legislación no es aplicable. En segundo lugar, dice que, aún en caso de que resultara aplicable, la parte debería "procurar al juzgador una certificación expedida por la autoridad diplomática alemana acreditativa de la normativa vigente en dicho Estado que resulte de aplicación al caso, debidamente acreditada", y en cambio se ha limitado a "exponer sucintamente cuáles son los criterios indemnizatorios existentes en Derecho Alemán, pero sin citar ni probar la legislación alemana aplicable". Por estos motivos no podría admitirse la prueba del Derecho extranjero en este supuesto (Id. vLex: VLEX-57889023).

${ }_{17} \mathrm{Vid}$. SAP de Madrid de 22 de diciembre de 2008. Sentencia en la que resulta aplicable la legislación mexicana, y que dispone: "La Ley aplicable es (...) la Ley Mejicana (...) sin que exista reenvío a la Ley Española en cuanto el artículo 13 del vigente Código Civil Federal de México de 1928 no contempla expresamente el supuesto que nos ocupa» (Id. vLex: VLEX53889881). Se pronuncia expresamente acerca de las normas de conflicto de la ley extranjera.
} 
c) La vigencia y existencia del Derecho extranjero;

d) La interpretación concreta de las normas del Derecho extranjero; y

e) La aplicabilidad del Derecho extranjero al caso concreto ${ }^{18}$.

La persona que invoque el Derecho extranjero deberá acreditar su contenido y vigencia por los medios de prueba admitidos en la ley española, sin embargo, para su aplicación "el Juzgador podrá valerse además de cuantos instrumentos de averiguación considere necesarios, dictando al efecto las providencias oportunas"; interpretando este precepto ${ }^{19}$, por lo que:

1. Quien invoca el Derecho extranjero deberá "acreditar en juicio la existencia de la legislación que solicita, la vigencia de la misma, y su aplicación al caso litigioso" ${ }^{20}$. Pues se razona que "la aplicación del Derecho extranjero es una cuestión de hecho, y como tal ha de ser alegada y probada por la parte que lo invoca";

2. Se estructura a nivel legal y jurisprudencial: una amplia facultad investigadora que tiene el juez de instancia a la hora de determinar el Derecho extranjero aplicable, no quedando vinculado por las aportaciones de las partes en la que razona que: "Aunque en sentido genérico se habla, en efecto, de la prueba del Derecho extranjero, criterio que responde en España a una tradición que arranca de la L. 18, Tít. 14 de la Partida $3^{\mathrm{a}}$, la evolución doctrinal y jurisprudencial nunca equiparó en sentido estricto la prueba del Derecho extranjero con la prueba de los hechos, pues se ha entendido que no son supuestos idénticos la justificación o acreditación de la norma extranjera y la prueba de los hechos. Se ha hecho notar, en este sentido, que el iura novit curia, aun atenuado respecto del Derecho extranjero no se excluye como principio en cuanto al conocimiento de las normas no nacionales, si bien las partes deben cooperar con el juez en la busca de la norma extranjera suministrándole los medios de conocimiento, de manera que más que una actividad probatoria en sentido estricto se trata de una colaboración entre las partes y el órgano. En nuestro sistema procesal vigente, tras la redacción del Título Preliminar del Código Civil, el artículo 12.6 deja claro: a) que la norma extranjera se "acredita"; b) que en su función de aplicador el Juzgador puede valerse de cuantos instrumentos de averiguación considere oportunos. El término "acreditar" no está empleado de manera vulgar, sino en sentido técnico, lo cual significa que no es necesario que la verificación o comprobación del contenido y vigencia de la norma extranjera se ajuste a las reglas de la prueba rigurosa, sino que responde a los postulados más abiertos de la prueba denominada doctrinalmente "libre", o en otras palabras, prueba que presupone la libertad de medios probatorios (siempre que sean lícitos y se obtengan por medios no prohibidos), y la libertad de valoración o apreciación. Si el juzgador, con la aportación de las partes no se considera suficientemente ilustrado debe y puede actuar de oficio e investigar la norma aplicable";

3. Es posible el uso de las diligencias finales para lograr un conocimiento adecuado del Derecho extranjero aplicable, máxime cuando se alegan normas extranjeras y se acreditan en forma defectuosa o contradictoria; y

4. Cuando el Derecho extranjero no ha quedado probado en forma alguna o con la suficiente claridad o seguridad, lo procedente no es desestimar la demanda, sino aplicar la legislación española.

Por tanto, para ser eficaces en la prueba del Derecho extranjero será recomendable probar no sólo la exacta entidad del Derecho vigente, sino su alcance y autorizada interpretación, de suerte que su aplicación no suscite la menor duda razonable a los Tribunales españoles, y todo ello mediante la pertinente documentación fehaciente.

${ }^{18} \mathrm{Vid}$. STS de 27 de diciembre de 2006, que señala que "existe una numerosa y consolidada jurisprudencia sobre la necesidad de probar, por quien se alega o invoca o postula la aplicación del Derecho extranjero, la existencia, el contenido y la vigencia de la norma cuya aplicación se pretende."

${ }^{19}$ Vid. STSJ de Madrid de 11 de enero de 1999. (Id. vLex: VLEX-478598210).

${ }^{20}$ Vid. STS de 3 febrero de 1975 y de 31 de diciembre de 1994, que hacen expresa referencia de que la prueba corresponde a quien invoca el Derecho extranjero. (Id. vLex: VLEX-73629183). 
No cabe confundir la prueba de "legislación" vigente en un determinado territorio, con la prueba "del Derecho" aplicable, concepto este referido a la forma en la que la sociedad y los tribunales de aquel lugar solucionan sus conflictos, no siempre mediante la aplicación de legislación formalmente promulgada, lo que, por lo demás, constituye un hecho notorio en aquellos países en los que rige el common law. El tribunal del foro debe fallar como lo haría un tribunal extranjero.

De esta última interpretación, sacamos varias ideas:

a) En principio, todas las normas extranjeras son de aplicación. La remisión que hace la norma de conflicto española al Derecho extranjero es íntegra. No solo se incluyen las normas de Derecho interno, sino las normas especiales de Derecho extranjero y las de extensión. Pero el juez español no aplicará la norma de conflicto española salvo que se admita el reenvío por retorno y el reenvío de segundo grado;

b) Debe aplicarse toda fuente extranjera de la que emanan las leyes, incluso instituciones jurídicas de origen extranjero;

c) El Derecho extranjero debe aplicarse con la interpretación dada por sus tribunales; y

d) Se aplicarán las normas de Derecho público o privado siempre que tengan efecto sobre los particulares.

\section{Medios de prueba del Derecho extranjero}

12. En relación con los medios de prueba del Derecho extranjero ${ }^{21}$ el TS, entre otras, en la sentencia de 4 de julio de $2006^{22}$ pone de relieve la posibilidad de utilizar "todos los medios de prueba a su alcance", que venimos a enumerar:

a) Documentos públicos o intervenidos por fedatarios públicos que pueden aportarse al proceso mediante las correspondientes certificaciones: el documento extendido por fedatario público es el medio de prueba más extendido en nuestros Tribunales, y que, aunque venga a determinar la vigencia y contenido, queda limitado por la falta de interpretación y de aplicación de la norma al caso concreto ${ }^{23}$. La propia alusión en la interpretación de la normativa a aplicar, hecho muy necesario en cualquier litigio, va a restar fuerza probatoria y deberemos complementarla. Estas certificaciones son fáciles y rápidas de conseguir, pero tienen el inconveniente de que no pueden probar el contenido de tal derecho, su alcance o su aplicabilidad. Tan sólo pueden probar su texto literal y, en su caso, la vigencia del mismo. ${ }^{24}$

b) Prueba pericial: consiste en un informe elaborado por "expertos en el Derecho extranjero" que se quiere probar, así lo establece el artículo 335 de la LEC ${ }^{25}$. Los "expertos" pueden ser tanto del país cuyo Derecho se trata de probar como de otra nacionalidad incluso española.

${ }^{21}$ El artículo 281.2 de la LEC establece la necesidad de probar el Derecho extranjero, pero no hace especial referencia a los medios que se pueden utilizar para llevar a cabo tal tarea. Con la nueva regulación, la jurisprudencia ha desarrollado el precepto de la LEC de la misma forma que se aplicaba el del Código Civil, de manera que debe probarse por los medios de prueba principalmente recogidos en el artículo 299 de la LEC. La jurisprudencia da especial importancia a dos medios: la prueba documental y la prueba pericial.

${ }^{22}$ La Sentencia señala lo siguiente: "quien debe probar la existencia y vigencia del derecho que debe ser aplicado a la relación jurídica de que se trate (...) mediante testimonio conforme de dos jurisconsultos del país respectivo aportado por los autos" (Id. vLex: VLEX-24297593).

${ }^{23}$ Artículo 317 de la LEC: "tipos de documentos públicos en el ámbito general en materia civil."

${ }^{24}$ Vid. J. C. Fernández Rozas/ S. SÁnchez Lorenzo, Derecho Internacional Privado, Civitas, 7 a edición, 2013. p. 177.

${ }^{25}$ Artículo 335 de la LEC que establece lo siguiente: "1. Cuando sean necesarios conocimientos científicos, artísticos, técnicos o prácticos para valorar hechos o circunstancias relevantes en el asunto o adquirir certeza sobre ellos, las partes podrán aportar al proceso el dictamen de peritos que posean los conocimientos correspondientes o solicitar, en los casos previstos en esta ley, que se emita dictamen por perito designado por el tribunal. 2. Al emitir el dictamen, todo perito deberá manifestar, bajo juramento o promesa de decir verdad, que ha actuado y, en su caso, actuará con la mayor objetividad posible, tomando en consideración tanto lo que pueda favorecer como lo que sea susceptible de causar perjuicio a cualquiera de las partes, y que conoce las sanciones penales en las que podría incurrir si incumpliere su deber como perito. 3. Salvo acuerdo en contrario de 
Este es el medio de prueba más completo y que puede y debe probar no sólo la vigencia y contenido del Derecho extranjero sino también su interpretación y aplicación al caso concreto, como complemento a la documental pública. Sin embargo, no es un medio de prueba admisible el llamado "informe de parte", un informe redactado por expertos legales a instancia de una parte, en el que el experto "toma partido" en favor de las pretensiones concretas de la parte. ${ }^{26}$

c) Sobre los documentos privados: debe ser inadmitida la aportación de simples copias de normas seleccionadas, ya sean fotocopiadas o simplemente transcritas y copiadas de Internet; obviamente, no prueban la vigencia y/contenido del Derecho aplicable. La aportación de colecciones privadas y textos autorizados de doctrina extranjera puede constituirse como complemento del resto de pruebas sin que pueda constatarse la certeza. Aunque la jurisprudencia del TS ha sido reacia durante años a admitir estos documentos para probar el Derecho extranjero, no hay por qué eliminarlos radicalmente como "medios de acreditación del Derecho extranjero". Habrá que decidir en cada caso concreto si un determinado documento privado, como por ejemplo un autorizado texto doctrinal extranjero, puede servir para acreditar el Derecho extranjero "con certeza" 27.

13. Debemos indicar también que el artículo 33.4 de la LCJI indica que ningún dictamen vinculará a los órganos judiciales internacionales, como ya había indicado la jurisprudencia tiempo atrás. La solución que debe aportar en un eventual avance jurisprudencial, debe limitar la aportación probatoria al mero conocimiento del juez respecto a la vigencia, contenido e interpretación del Derecho extranjero ${ }^{28}$. El artículo 33.2 de la LCJI determina que los tribunales determinarán el valor probatorio de la prueba practicada de acuerdo con las leyes de la "sana crítica". Este precepto destaca un avance respecto a la línea dura que representa la jurisprudencia, por lo que el juez será libre de verificar la acreditación del Derecho extranjero, sin que exija todos los medios que pide el TS, aunque puede darse el caso de que el juez pida aún más pruebas al no quedar convencido ${ }^{29}$.

En la SAP de Baleares de 13 de diciembre de 2018, la parte demandada VICTORIUS SSHIPPING COMPANY N.V., en su escrito de contestación a la demanda, niega ser la titular de la embarcación sin identificar a quien pudiera serlo, no acompañando documentación alguna y anunciando la incorporación de dictámenes de expertos en derecho neerlandés sobre la titularidad del bien y la identidad de las personas jurídicas.

\section{Consecuencias de la no alegación o prueba del Derecho extranjero}

14. Es supuesto bastante común que alguna de las partes no pueda alegar o, incluso, probar el Derecho extranjero. La LEC no ofrece soluciones a tales supuestos, por lo que ha sido tanto la doctrina

las partes, no se podrá solicitar dictamen a un perito que hubiera intervenido en una mediación o arbitraje relacionados con el mismo asunto".

${ }^{26}$ Vid. SAP Tarragona de 13 abril de 2011. "El demandado ha acreditado la vigencia del derecho común a los litigantes con la certificación del Cónsul de Holanda, y el derecho aplicable por medio de los informes de los letrados holandeses oportunamente aportados a los autos" (Id. vLex: VLEX-354534758).

${ }^{27} \mathrm{Vid}$. SAP de Madrid 12 abril de 2011. "No haberse acreditado el derecho extranjero de aplicación al caso, "tanto en lo que respecta a su contenido como a su vigencia, dada la no exigencia de su conocimiento por los jueces y tribunales españoles" considerándose insuficiente, al respecto, las fotocopias de la legislación rumana que, no traducidas al castellano, se aportaron junto con el escrito rector del procedimiento" (Id. vLex: VLEX-354522342).

${ }^{28} \mathrm{El}$ artículo 33.4 recoge la última novedad en este campo. Según la jurisprudencia del TS el dictamen pericial debía ser elaborado por dos jurisconsultos de nacionalidad del Estado cuyo derecho es objeto de prueba. Con el artículo 33.4 LCJI, se abre la posibilidad a todos aquellos informes o dictámenes realizados por un experto, con independencia de su nacionalidad. Es decir, sin tener en cuenta la nacionalidad de quién los emite. Además, a diferencia del art. 281.2 LEC, el art. 33.4 LCJI, recoge que ningún informe, ya sea nacional o internacional, tendrá carácter vinculante para los operadores jurídicos.

${ }^{29} \mathrm{El}$ artículo 33.2 LCJI recoge expresamente (a diferencia del art. 281.2 LEC) que los jueces deberán aplicar las reglas de la sana crítica para determinar el valor probatorio de la prueba practicada para acreditar el contenido y vigencia del derecho extranjero. 
como la jurisprudencia las que han establecido distintas tesis para solucionar la cuestión, que van desde la tesis de la aplicación de oficio del Derecho extranjero ${ }^{30}$ a la tesis de la desestimación de la demanda ${ }^{31}$.

15. Tras la aprobación de la LCJI, su artículo 33.3 establece que, con carácter excepcional, se aplicara el Derecho material español cuando no se haya podido acreditar el Derecho extranjero ${ }^{32}$. Por lo tanto, ha obtenido reconocimiento legal esta última tesis. Defiende que se aplique el Derecho material español por falta de alegación y prueba del Derecho extranjero, ello evita la denegación de justicia y la vulneración del artículo 24 de la CE.

De esta forma, consagra al Derecho extranjero como un "hecho procesal", por lo que si no se alega ni se prueba, desaparece del proceso, pero, como aclaramos anteriormente, no es un mero hecho procesal; aparte de serlo, cuenta con particularidades que hacen considerarlo más que un hecho ${ }^{33}$.

Esta tesis ha sido ampliamente seguida desde los comienzos del problema de la aplicación del Derecho extranjero en el siglo XIX, así se recoge en las sentencias del Tribunal Supremo ${ }^{34}$. Ha llegado también al Tribunal Constitucional, que considera que es la solución que más respeta los preceptos constitucionales ${ }^{35} \mathrm{y}$ es la más seguida por los tribunales inferiores ${ }^{36}$.

${ }^{30}$ Tesis por la que debe aplicarse de oficio el Derecho extranjero debido al carácter imperativo que tienen las normas de conflicto españolas que dicta el artículo 12.6 del Código Civil, pero tal argumento no es suficiente porque el sistema español de alegación y prueba del derecho extranjero está diseñado para que la carga de la prueba recaiga sobre las partes según el artículo 282 de la LEC, precepto que se aplica al artículo 281.2 de la LEC cuando se determina que el tribunal puede valerse de cualquier medio de prueba necesario para su aplicación. Aunque explícitamente se dice "la carga de la prueba", puede darse el caso de una interpretación amplia y extenderse a la alegación del derecho, de esta manera, podemos pensar que el tribunal realiza la labor de las partes corrigiendo sus errores. No debe aplicarse tal tesis debido a que va en contra del principio de congruencia de la sentencia, el principio dispositivo, y el de justicia rogada.

${ }^{31}$ Es una de las tesis más defendidas. Si un litigio debe regirse por el Derecho extranjero, y argumenta sobre la base del Derecho español, tal parte debe ver desestimada sus pretensiones. Sus argumentos a favor se basan en la imposibilidad de la aplicación de oficio del Derecho extranjero, pero que también prohíbe aplicar directamente el Derecho español, además de que el tribunal no tiene la obligación de aplicar el Derecho extranjero porque tal obligación recae sobre las partes. Además, el tribunal no es quien, para hacer el trabajo incorrectamente hecho por el abogado de una parte, o incluso de las dos partes, que intentan encuadrar un caso mediante la aplicación del Derecho español cuando deba aplicarse el Derecho extranjero. Refuerza la seguridad jurídica, porque el caso no se resolverá con otro Derecho salvo el indicado en la norma. No se deniega la justicia, por lo que no supone un non liquet, y no se incumple el principio de tutela judicial efectiva ya que la demanda se ha valorado como tal y se ha dado respuesta a una pretensión solicitada por la parte correspondiente. Produce además un efecto de "cosa juzgada limitado" porque una vez desestimada - sin entrar a discutir sobre el fondo del asunto-la parte que ha visto desestimada su pretensión puede volver a presentar la demanda argumentando con una causa de pedir distinta.

${ }^{32}$ El artículo 33.3 de la LCJI ha supuesto un cambio en cuanto a la consideración del derecho extranjero en el procedimiento judicial. Con anterioridad al nuevo artículo, la doctrina mayoritaria defendía el carácter híbrido de la norma extranjera al considerarla como un tertium genus entre el derecho y los hechos procesales, a tenor del artículo 281.2 de la LEC, puesto que no especifica en concreto a quién corresponde probar el derecho extranjero, abriendo la posibilidad tanto a las partes (hecho) como a los órganos judiciales (derecho). En cambio, la jurisprudencia del TS, salvo alguna excepción, ha optado por considerarlo como un hecho procesal, al interpretar el artículo 281.2 de la LEC en el sentido del derogado artículo 12.6.II del CC, el cual atribuía de forma expresa la carga probatoria a las partes.

33 Vid. SAP de Cádiz de 13 de marzo de 2017(Id. vLex: VLEX-342362526).

${ }^{34}$ Ha sido sostenida por la Sala Primera del TS de 16 de diciembre de 1960, al señalar que "cuando no se alega ni se acoge nadie (en el) momento procesal oportuno a lo que dispone el artículo 10, párrafo segundo el Código Civil, los Tribunales no puedan declinar la aplicación de nuestras Leyes" renunciando a su imperio y de oficio el minar el Código Civil y aplicar su derecho extranjero que no tienen por qué conocer y que, al no alegarlo los interesados, ha de entenderse que prescindan o renuncian a su aplicación." En el mismo sentido se pronuncia el TS de 30 abril de 2008. "La sentencia impugnada que, en consecuencia, no ha infringido ninguno de los citados preceptos al aplicar correctamente al caso la norma de conflicto y, posteriormente, lo previsto en el derecho español ante la falta de acreditación del contenido y alcance del derecho extranjero, extremos que el juzgador no estaba obligado a investigar de oficio."

${ }^{35} \mathrm{Vid}$. STC de 2 de julio de 2001. "Todo ello contrariando, a la hora de aplicar la legalidad vigente, la doctrina sentada en la materia por el Tribunal Supremo de deberse estar, en defecto de prueba del Derecho extranjero invocado en el proceso, al Derecho español, según se desprende de una reiterada jurisprudencia. Doctrina jurisprudencial que, ciertamente, es más respetuosa con el contenido del artículo 24.1 de la CE que la solución adoptada por la Sentencia impugnada de tener por decaída la demanda, dado que el Derecho español, con carácter sustitutorio del que resulta aplicable, también puede ofrecer en una situación de tráfico externo la respuesta fundada en Derecho que el citado precepto constitucional exige" (Id. vLex vid. cita 35).

${ }^{36} \mathrm{Vid}$. SAP de Barcelona de 30 de junio de 2006, que establece que: "en consecuencia, y no habiéndose efectuado prueba en tal sentido, aun en el caso de que fuera admisible la aplicación del derecho extranjero, que no lo es, tampoco podría aplicarse por desconocerse su contenido, debiendo acudir a la legislación española, como así efectúa el juzgador de instancia.” 
Pero debemos decir en contra de esta tesis y, en contraposición con la tesis de la desestimación de la demanda, que la presente teoría: 1) vulnera el carácter imperativo de las normas de conflicto españolas; 2) comporta inseguridad jurídica porque no se sabe, en un principio, que derecho se va a aplicar; y 3) favorece las conductas estratégicas a la hora de elegir el Derecho aplicable.

Por último, también se ha argumentado contra esta solución, que favorece estrategias de los particulares para aplicar el Derecho español cuando no es realmente aplicable al supuesto. ${ }^{37}$

\section{Aplicación de la Lex Loci Delicti Commissi}

16. En el caso que nos ocupa la Audiencia Provincial de Baleares opta por la aplicación de la Ley del lugar donde se produce el daño (= Lex Loci Delicti Commissi). Se trata del criterio Lex Damni $o$ Erfolgsort (=Ley del lugar donde se produce el daño derivado del hecho ilícito). El criterio Lex Loci Delicti Commissi permite una identificación segura y veloz de la Ley aplicable, y conduce, en condiciones normales, a la Ley del Estado cuya aplicación al caso es la más previsible para las partes implicadas. Ello significa que la Lex Loci Delicti Commissi suele ser la Ley cuya aplicación suscita los costes conflictuales más reducidos para los sujetos implicados en los casos internacionales de obligaciones extracontractuales. Dicha Ley sintoniza perfectamente con las expectativas de los sujetos implicados. En efecto, la Lex Loci Delicti Commissi suele corresponder al país "más estrechamente vinculado" al supuesto. Los costes de información de dicha Ley y los costes de adaptación de los particulares al contenido de dicha Ley, son reducidos para las partes. ${ }^{38}$

Para concretar qué espacios físicos conforman el territorio de un Estado, es preciso consultar los criterios clásicos de Derecho internacional público. Es territorio de un Estado la tierra firme del mismo, el Mar territorial y el espacio aéreo del Estado en cuestión. Las Embajadas y otras Delegaciones diplomáticas de países extranjeros gozan, como es sabido, de ciertas "inmunidades legales", pero pertenecen al territorio del Estado donde se hallan situadas.

Así se puede observar en la SAP de Baleares de 13 de diciembre de 2018, en la que la pretensión se fundamenta en que el buque "Dwinger" se hallaba fondeado en Cala jondal, y que enganchó un cable submarino de fibra óptica propiedad de la actora que enlazaba las islas de Ibiza y Formentera, privando a éstas del servicio de datos (ADSL y 3G) prestado por la demandante. Además, esa localización coincide con la que se refleja en el diario de navegación del buque incorporado a las actuaciones $\left(38^{\circ}, 51,733 \mathrm{~N}\right)$. Por lo que queda claro que el daño se produce en territorio español.

17. Además, el Reglamento "Roma II" establece normas de conflicto especiales para determinadas acciones por responsabilidad extracontractuales ${ }^{39}$.

Así lo establece la SAP de Baleares de 13 de diciembre de 2018 señalando en los fundamentos jurídicos que en el procedimiento concurre elemento extranjero por el pabellón del "Dwinger" y la nacionalidad holandesa de las entidades codemandadas por lo que debe precisarse la normativa aplicable. Comenta que la legislación procesal española es la aplicable al procedimiento en curso conforme al artículo 3 de la LEC y que la naturaleza extracontractual de la responsabilidad que se pretende hace aplicable el Reglamento "Roma II", conforme a sus artículos 1 a 3; lo que, a su vez, determina de acuerdo con su artículo 4, la aplicación de la ley española al haberse producido el daño en territorio nacional. La ley española, como Ley aplicable, se extiende a todo lo señalado en el artículo 15.

${ }^{37} \mathrm{Vid}$. STS de 19 de febrero de 1990, que señala que: "la falta de alegación y prueba no puede conducir, como pretende el recurrente en el motivo séptimo, a la aplicación de la ley española, pues ello equivaldría al absurdo de sancionar la omisión de prueba deliberadamente querida de la norma extranjera, con la aplicación de la ley española, cuando se considerase que ésta era más beneficiosa" (Id. vLex: vid. cita 66).

38 Vid. A. L. Calvo Caravaca, El Reglamento Roma II, Comares, Granada, 2008, pp. 53-133.

${ }^{39}$ Las reglas especiales se han previsto para aquellos casos en los que el criterio locus damni se entiende que no es el adecuado para resolver ciertas categorías de ilícitos tendiéndose a la especialización por materias. Las mencionadas categorías son: (A) responsabilidad del fabricante por los productos; (B) competencia desleal y actos que restrinjan la libre competencia; (C) daños al medioambiente; (D) infracción de los derechos de la propiedad industrial e intelectual; y (E) la acción de conflicto colectivo. 


\section{Consideraciones finales}

18. En el Derecho internacional privado español la cuestión de la aplicación del Derecho extranjero ha entrado en una nueva dimensión con ocasión de la regulación ofrecida sobre el tema por la LEC y la LCJI. Los artículos $281.2^{\circ}$ y 282 de la LEC y el 33 de la LCJI dan cuerpo a un sistema de prueba del Derecho extranjero de textura abierta, de modo que serán siempre las partes o siempre el juez los que deban, en todos casos, probar el Derecho extranjero. En los casos en los que se aplica Derecho extranjero, la parte interesada en su aplicación deberá: primero, fundamentar su demanda en el Derecho extranjero y, segundo, probar el Derecho extranjero. Así se aprecia en la SAP de Baleares de 13 de diciembre de 2018, donde la parte demandada presenta dos informes sobre el Derecho extranjero, el Tribunal rechaza ambos informes señalando que en ellos no se aprecia ninguna especialidad del derecho extranjero sobre la titularidad del bien, respecto al informe sobre la legitimación pasiva conforme al derecho de Curazao y Holanda resultaba innecesario tratándose de una obligación no contractual.

19. En el caso en el que las partes argumenten en base al Derecho extranjero, pero no lo prueban: el tribunal deberá advertir a las partes de las consecuencias que tendrá el no hacerlo (= artículo 429.1.II LEC). Si pese a ello, las partes no prueban el Derecho extranjero, éste no podrá aplicarse y el tribunal tampoco deberá probarlo por lo que dictará sentencia y desestimará las pretensiones de las partes.

20. Tal como sucede en la SAP de Baleares de 13 de diciembre, en primera Instancia, se desestimó la demanda presentada por la demandante por lo que se interpuso recurso de apelación. Dado que en el procedimiento concurre elemento extranjero atendido que el pabellón del "Dwinger" tiene nacionalidad holandesa, debe precisarse la normativa aplicable. El tribunal señala que la legislación procesal española es la aplicable al procedimiento en curso conforme al artículo 3 de la LEC, la naturaleza extracontractual de la responsabilidad que se pretende hace aplicable el Reglamento "Roma II", conforme a sus artículos 1 a 3, lo que, a su vez, determina de acuerdo con su artículo 4, la aplicación de la ley española al haberse producido el daño en territorio nacional. Partiendo de la normativa aplicable y del nuevo examen de la prueba practicada, él Tribunal considera que fue el buque "Dwinger" el que dañó el cable submarino, por lo que se estima la demanda y se deja sin efecto la anterior resolución condenando a la parte demandada a pagar la cantidad solicitada por la demandante y al pago de las costas procesales; y todo ello en aplicación de la ley española (= Lex Loci Delicti Commissi). 